\title{
VIOLÊNCIA DOMÉSTICA E SEXUAL CONTRA A MULHER: REVISÃO INTEGRATIVA
}

\author{
F. S. Oliveira ${ }^{1}$, L. M. Araújo ${ }^{1}$, L. L. Silva ${ }^{1}$, Z. M. Crispim ${ }^{1}$, V. B. D. B. Lucindo ${ }^{1}$, L. N. Oliveira ${ }^{2, *}$ \\ ${ }^{1}$ Centro Universitário de Anápolis - UniEvangélica/Anápolis-GO, Brasil \\ ${ }^{2}$ Instituto Federal de Educação, Ciência e Tecnologia de Goiás - IFG/Campus Goiânia-GO, Brasil \\ lucas@ifg.edu.br*
}

Submetido 01/09/2015 - Aceito 13/12/2017

DOI: $10.15628 /$ holos.2017.1903

\section{RESUMO}

A violência doméstica e sexual atinge mulheres de todas as classes sociais, raças e culturas. Afetando assim o bem-estar, a segurança, o desenvolvimento pessoal, profissional, e acima de tudo a autoestima das mulheres, tornando-as frágeis e inseguras. O estudo teve como objetivo analisar a violência doméstica e sexual sofrida pela mulher brasileira e trata-se de uma revisão integrativa da literatura das publicações nos periódicos indexados nas bases de dados Literatura Latino-Americana em Ciências da Saúde (LILACS) e Scientific Electronic Library Online (SciELO). A busca dos artigos foi realizada por meio dos descritores: violência contra a mulher, violência doméstica, maus-tratos conjugais, mulheres mal tratadas, foram selecionados 12 artigos.
O estudo mostrou que tem maior ocorrência de tais atos no país quando associados ao o uso de álcool (26\%) das agressões cometidas, após a mulher sofrer algum tipo de agressão tem maior chance de desencadear fatores como ansiedade (15,15\%) medo (12,12\%), vergonha $(12,12 \%)$, isolamento social $(9,09 \%)$. A pesquisa mostrou que a violência contra a mulher ainda se encontra oculta nos lares brasileiros, embora na maioria das vezes não seja denunciada por medo dos agressores e por vergonha da exposição. Observou-se também que as principais causas de violência são o ciúme, a ingestão de bebida alcoólica e o uso de drogas. Essas atitudes violentas frequentemente ocasionam nas mulheres problemas de ansiedade, depressão e até suicídio.

PALAVRAS-CHAVE: Violência contra a mulher, maus-tratos conjugais, mulheres mal tratadas.

\section{DOMESTIC AND SEXUAL VIOLENCE AGAINST WOMEN: INTEGRATIVE REVIEW}

\begin{abstract}
The domestic and sexual violence affects women of all social classes, races and cultures. Thus affecting the welfare, safety, personal development, professional, and above all self-esteem of women, making them fragile and insecure. The study aimed to analyze the domestic and sexual violence against women by Brazil and is an integrative literature review of publications in journals indexed in the databases of Latin American Literature in Health Sciences (LILACS) and Scientific Electronic Library Online (SciELO). The search of articles was performed by using the descriptors: violence against women, domestic violence, spouse abuse, abused women, was selected 12 articles. The study
\end{abstract}

showed that it has a higher occurrence of such acts in the country when associated with alcohol use $(26 \%)$ of assaults committed after women suffer some type of aggression are more likely to trigger factors such as anxiety (15.15) fear (12.12), shame (12.12), social isolation (9.09\%). Research has shown that violence against women is still hidden in the Brazilian homes, although in most cases not reported for fear of the aggressor and the shame of exposure. It was also observed that the main causes of violence are jealousy, alcohol consumption and drug use. These often cause violent behavior in women problems of anxiety, depression and even suicide.

KEYWORDS: Violence against women, domestic violence, spouse abuse, abused women. 


\section{INTRODUÇÃO}

A necessidade de prevenir e combater a violência no ambiente doméstico e no meio social é uma das preocupações para as políticas públicas de saúde. No Brasil desde a década de 60, movimentos feministas já utilizavam estratégias para garantir os direitos à vida, a liberdade, a segurança, a informação, a privacidade e saúde. A violência contra a mulher consiste em todo ato de violência de gênero que possa resultar em quaisquer danos físicos, como tapa, empurrão, chacoalhão, soco, chutes ou surras, estrangulamento ou uso/ ameaça de arma de fogo ou branca; sexual: relação sexual forçada, relação sexual por coação ou medo, e prática sexual degradante ou humilhante forçada, ou psicológica: insulto humilhação, intimidação ou ameaça (GOMES, 2007; OLIVEIRA, 2008; SAFFIOTI, 2001). Numa cultura machista, o homem tem papel de dominação e autoridade sobre as mulheres, enquanto que a mulher é vista como o sexo frágil e responsável pelos afazeres domésticos como cuidar dos filhos, do lar, e a ser "submissa" aos desejos do homem. As agressões domésticas abrangem a violência psicológica e são caracterizadas por pressão moral e psicológica. A violência doméstica e sexual atinge mulheres de todas as classes sociais, raças e culturas, ao afetar assim, o bem-estar, a segurança, o desenvolvimento pessoal, profissional e, acima de tudo, a autoestima das mulheres, tornando-as frágeis e inseguras. Os motivos que levam a prática da violência são vários, desde o uso de drogas, a raiva, ignorância, demonstração de extremo poder e, principalmente a ingestão de bebidas alcoólicas (LEÔNCIO, 2008). Provavelmente, os homens que praticam violência contra suas parceiras têm uma história pregressa de haver vivenciado ou até mesmo sofrido algum tipo de violência da parte de seus pais, as quais podem interferir na sua idealização como homem. Estes acontecimentos tendem levá-los a reproduzir tais atos na sociedade e, principalmente no âmbito familiar (GOMES, 2007).

É importante ressaltar que durante alguns anos o conceito de violência restringia-se apenas a integridade corporal, para "qualquer pessoa maltratada" atualmente, foram acrescentados os sofrimentos morais e psicológicos. Entretanto, os "maus tratos" abrangem tudo o que uma pessoa faz e ou concorre para o sofrimento e a alienação de outra. Sendo que na atual legislação brasileira, novos instrumentos foram criados para protegerem, especificamente a figura da mulher, na intenção de coibir uma das mais antigas formas de violência, aquela desferida às pessoas do sexo feminino (TONET, 2007; WILHELM, 2007). Deste modo, com o objetivo de erradicar a violência e punir os agressores, promover a assistência e proteger às mulheres foi criada, em 25 de novembro de 2004, a lei n⒒ 340, mais conhecida, como Lei Maria da Penha. No Art. 30 a referida lei cita garantias a toda mulher, como por exemplo: direito à vida, à segurança, à saúde, à alimentação, à educação, à cultura, à moradia, ao acesso à justiça, ao esporte, ao lazer, ao trabalho, à cidadania, à liberdade, à dignidade, ao respeito e à convivência familiar e comunitária (Constituição federal 2006). A realidade conduz a acreditar que a nova legislação oferece o reconhecimento da violência contra as mulheres, identifica o problema social, e tecerá providências para o combate por meio de políticas públicas na intenção de colocar a mulher no centro do debate.

Nesse contexto, esta pesquisa fornece uma revisão integrativa da literatura nacional na intenção de responder a seguinte questão: Por que as mulheres são tão agredidas por seus parceiros? Portanto, a relevância do estudo está fundamentada na possibilidade de buscar a importância das relações entre homens e mulheres com possibilidades de igualdade e respeito mútuo no âmbito social. Dessa forma, o interesse em realizar essa pesquisa originou-se da 
importância em demonstrar quais os danos causados a essas mulheres agredidas, os motivos que levam os seus parceiros a cometerem violência, e o tipo de reação que elas apresentam. Deste modo, o estudo tem o objetivo de analisar a violência doméstica e sexual sofrida pela mulher brasileira.

\section{METODOLOGIA}

Nesta revisão, a importância da metodologia consiste na análise de pesquisas relevantes, propondo diferenciar a tomada de decisão e a melhoria da prática clínica, possibilitando o avanço do conhecimento (MENDES; SILVEIRA; GALVÃO, 2008). Para a elaboração da pesquisa, determinou-se primeiramente o assunto, o tema violência contra a mulher surgiu, pela alta incidência de agressões no país e, consequentemente está ocorrendo ampla discussão sobre fatos, que constituem problemas de saúde pública, portanto é um tema atual. Para responder a problemática do tema adotou-se a seguinte questão norteadora: Por que as mulheres são tão agredidas por seus parceiros? No segundo passo determinou-se os critérios de inclusão e exclusão dos estudos. O critério de inclusão para a busca dos estudos foi: publicações em periódicos nacionais indexados na Literatura Latino-Americana e do Caribe em Ciências da Saúde (LILACS) e Scientific Electronic Library Online (SCIELO) no período de 2007 a 2011, foram excluídos todos os artigos que não se enquadraram na pesquisa. Para a busca dos artigos foram utilizados os seguintes descritores: violência doméstica e sexual contra a mulher, violência baseada em gênero, violência de gênero. Inicialmente foram identificados 10.499 artigos e, após refinamento em língua portuguesa, ano, descritores e base de dados foram selecionados para a pesquisa, após a leitura dos resumos, 12 artigos. Estes artigos selecionados são mencionados ao longo do texto (Resultados e Discussões). No terceiro passo, após leitura criteriosa foram expostas as informações coletadas por meio do instrumento de coleta de dados, elaborado com o objetivo de analisar os dados de forma clara e sucinta, expondo os resultados de maneira que possa: facilitar, caracterizar e conhecer o tema abordado. No quarto passo analisaram-se detalhadamente os estudos encontrados, descobrindo resultados diferentes ou que provocaram conflitos nos diferentes estudos. No quinto passo descreveram-se os principais resultados do estudo, que permitiram identificar as lacunas do tema abordado, conhecer sugestões pertinentes para futuras pesquisas e melhoria da prática clínica. No sexto passo descreveram-se as etapas percorridas pelos pesquisadores e os principais resultados obtidos evidenciados na análise dos artigos incluídos. Os artigos foram divididos pelos pesquisadores em duas categorias violência de gênero e violência doméstica e sexual contra a mulher, para a violência gênero foram utilizados 4 artigos, e para a violência domestica e sexual contra a mulher foram utilizados 8 artigos. Também para a determinação do nível de evidência foi utilizada a classificação das forças que é considerada em seis níveis: Nível quatro - evidência que emerge de estudo não experimental, descritivo ou com abordagem metodológica qualitativa ou estudo de caso. Nível cinco evidência que surge de relatório de caso ou dado obtido de forma sistemática, de qualidade verificável ou de dado de avaliação de programa (STETLER, 1998). 


\section{RESULTADOS E DISCUSSÃO}

Os resultados e a discussão dos artigos selecionados foram interpretados e relacionados com outros estudos com a finalidade de extrair uma síntese. A forma de apresentação foi a descritiva com a intenção de melhor reunir o conhecimento produzido. A Tabela 1 apresenta quais os motivos que predominaram e levaram ao ato de violência, a maior ocorrência foi o uso de álcool com (26\%) e drogas (17,3\%), apresentando apenas desemprego, ciúme (4,3\%), também mostra que após a mulher sofrer algum tipo de agressão tem chance de desencadear fatores como medo $(15,15 \%)$ ansiedade $(12,12)$ seguida de isolamento social $(9,09 \%)$, vários artigos $(15,15)$ não identificaram os danos causados pelas agressões.

Tabela 1 - Relação dos motivos da violência contra a mulher, tipo de reação das vítimas e os danos causados às mulheres agredidas.

\begin{tabular}{|c|c|c|c|c|c|}
\hline Motivos da violência & $\mathrm{N}^{\circ}$ & (\%) & Tipo de reação & $\mathrm{N}^{\circ}$ & $(\%)$ \\
\hline Álcool & 6 & 26 & Medo & 5 & 15,15 \\
\hline Drogas & 4 & 17,3 & Ansiedade & 4 & 12,12 \\
\hline Abuso de poder & 3 & 13 & Vergonha & 4 & 12,12 \\
\hline Desemprego & 2 & 8,6 & Isolamento social & 3 & 9,09 \\
\hline Ciúmes & 2 & 8,6 & $\begin{array}{l}\text { Aborto } \\
\text { espontâneo }\end{array}$ & 3 & 9,09 \\
\hline Recusa da separação conjugal & 1 & 4,3 & $\begin{array}{l}\text { Sentimento } \\
\text { culpa }\end{array}$ & 3 & 9,09 \\
\hline $\begin{array}{l}\text { Mudança de comportamento da } \\
\text { companheira }\end{array}$ & 1 & 4,3 & Depressão & 3 & 9,09 \\
\hline Sexo & 1 & 4,3 & Insônia & 2 & 6,06 \\
\hline Não identificado & 3 & 13 & $\begin{array}{l}\text { Sentimento de } \\
\text { inferioridade } \\
\text { Não identificado }\end{array}$ & $\begin{array}{l}1 \\
5\end{array}$ & $\begin{array}{l}3,03 \\
15,15\end{array}$ \\
\hline
\end{tabular}

Para Rabello e Caldas Júnior (2007) o motivo pelo qual surge a desestruturação da personalidade do agressor é o desemprego, que conduzirá a violência contra suas companheiras, ou também, refere-se a atos de violência que o homem já praticava na rua, e pela força do hábito passou a praticar em casa causando lesões corporais em suas parceiras.

O estudo de Zaleski (2010) teve como objetivo principal demonstrar que o uso de álcool pelo casal é um fator que leva ao ato da violência doméstica. Portanto as chances de agressão a mulher aumentam nove vezes quando os parceiros/companheiros são usuários de bebida alcoólica. Os dados levaram a afirmação de que quando alcoolizados, tanto mulheres quanto homens se envolveram em brigas familiares que levaram a algum tipo de agressão. Sendo que esse fato foi mais prevalente no gênero feminino, mais uma vez comprovando que a cultura patriarcal ainda é a Tonica nas famílias de baixa renda no Brasil. Os dados acima revelam que existem vários fatores que contribuem para a violência, mas o álcool unido a outras substâncias 
lidera entre os motivos, isso levará a dificuldade de identificar as vítimas, pela vergonha e o medo enfrentado pelas mulheres.

Para Wilhelm e Tonet (2007) a violência contra a mulher é um problema mundial e constitui um caso de saúde pública. Esse tipo de problema acarreta nas mulheres vítimas uma série de sintomas físicos e emocionais, tais como: ansiedade, medo, sentimento de inferioridade, insegurança, baixa autoestima e grande sofrimento psíquico, que requer tratamento diferenciado com analistas. E concluíram que cabe ao Estado realizar ações que visam a prevenção da violência e em caso de ocorrência da mesma, não só a mulher deve ser atendida, também o agressor deve ser instruído através de grupos de auto ajuda, no sentido de se melhorar o crescente quadro da violência.

Já em Villela e Lago (2007) determinam que os sintomas do abuso sexual são queixas físicas, cefaleia crônica, alterações gastrointestinais, dor pélvica, disfunção sexual, depressão, ansiedade, transtornos alimentares/obesidade, uso abusivo de drogas, infecções do trato reprodutivo. A mulher violentada pode apresentar uma série de sentimentos negativos como abandono do lar, separação, prostituição, medo da morte, solidão, vergonha, e até sensação de culpa (MONTEIRO; SOUZA, 2007). A reação das vítimas frente às agressões sofridas pelos seus parceiros pode levar a mulher apresentar vários fatores frente à sociedade como alta taxa medo (25\%), seguido de vergonha (20\%), apresentando menor índice sentimento de culpa (15\%) e isolamento social (20\%). Por outro lado Rabello e Caldas Júnior (2007) afirmam que as mulheres que sofrem agressões apresentam em $78 \%$ dos casos de ansiedade e insônia, sintomas somáticos $65 \%$, depressão grave $40 \%$, e disfunção social $26 \%$. O estudo também mostra que as mulheres agredidas sentem-se mais próximas e confiantes de pessoas estranhas que dos próprios familiares.

Já do ponto de vista de Barreto (2009) as manifestações ocorrem de forma diferenciada como doenças no sistema digestivo, circulatório, dores e tensões musculares, uso de entorpecentes, desordens menstruais, suicídio o que poderá levar ao assassinato tanto da vítima quanto do agressor.

Para um melhor andamento do trabalho e visando facilitar a leitura e entendimento das considerações levantadas, optou-se pela divisão dos estudos em duas categorias: Violência de Gênero e Violência Domestica e Sexual. Estas duas categorias foram de acordo com os estudos realizados as causas mais preponderantes em relação a casos de violência contra a mulher.

\section{Categoria I - Violência Gênero}

Muitas são as possibilidades de surgirem agressões contra a figura feminina, por vários motivos e principalmente pela cultura machista ainda vigente nas camadas menos providas de condição financeira ou ainda as de baixo nível cultural. Dentre os estudos que foram catalogados pode-se apurar que a maioria das violências são acometidas por pessoas do gênero masculino. Gomes (2007) realizaram uma pesquisa bibliográfica em escritos com data compreendida entre 1996 e 2007 que tratava sobre o estudo do gênero dos agressores contra a mulher, concluiu que a cultura patriarcal ainda domina entre as camadas mais pobres baixas da população, pensamento esse que considera a mulher como ser inferior e assim, ocorre a justificativa para a violência.

Também Couto (2007) se dedicou a descobrir as principais causas da violência contra as mulheres, entre pessoas de baixa renda e pouca instrução escolar. Apurou-se que as próprias mulheres aceitam esse tipo de atitude e entendem como uma forma de revide por algo errado que tenham praticado, e assim a agressividade tornou-se uma constante durante o relacionamento íntimo do casal. 
Conforme as informações de Leôncio (2008) pode-se constatar que o grande problema da violência cometida contra a mulher advém da cultura de submissão ao homem, na qual elas ainda devem ser vistas como seres obedientes, fieis aos seus parceiros, cuidadoras do lar, assim como compete a elas a educação da prole. Os autores acima mencionados realizaram um estudo analítico documental em 446 boletins de ocorrência devidamente formalizados na Delegacia de Defesa da Mulher na cidade de Ribeirão Preto-SP, entre os meses de outubro e novembro de 2006 com a conclusão de que a grande maioria da violência contra a mulher decorre diretamente de seus companheiros e que se repetiram ao longo dos anos sem que as agredidas tomassem medidas de repressão legal, por pura falta de acesso aos direitos jurídicos. O estudo aponta para a necessidade de maior atenção por parte das autoridades a fim de que sejam prevenidos e ou evitados esses acontecimentos.

Vieira, Perdona e Santos (2011) em um estudo transversal realizado com 504 mulheres com idade entre 15 e 49 anos em várias unidades básicas de saúde de Ribeirão Preto, São Paulo, buscaram mapear o gênero do agressor e estimar a prevalência da violência contra a mulher. $O$ estudo afirmou que a questão é tão complexa que não existe a possibilidade de se afirmar com exatidão quais motivos são mais prevalentes para que aconteça o abuso e a violência, embora, o uso do álcool, drogas e problemas financeiros devem predominar. As autoridades necessitam implantar políticas públicas no sentido de diminuir a alta incidência da violência entre as pessoas de baixa renda.

Na Tabela 2, têm-se os artigos relacionados à violência de gênero indicando a classificação das forças, sendo que $75 \%$ doa artigos obtiveram nível 4.

Tabela 2. Artigos relacionados à violência de gênero.

\begin{tabular}{|c|c|c|c|c|}
\hline Estudo/Ano & $\begin{array}{lll}\text { Título/ Tipo } & \text { de } \\
\text { estudo } & & \end{array}$ & Periódico & Autores & Evidência/Nível \\
\hline E1/ 2007 & 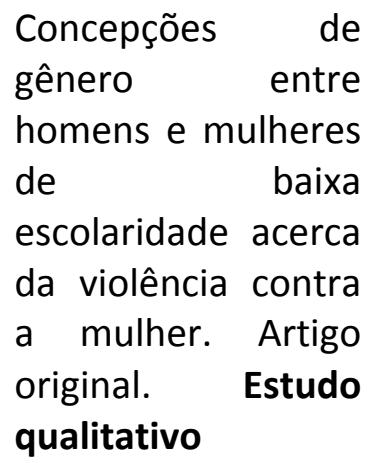 & $\begin{array}{l}\text { Ciência \& Saúde } \\
\text { Coletiva }\end{array}$ & $\begin{array}{l}\text { Couto, M.T } \\
\text { Scheraiber, B. L } \\
\text { Oliveira, } d^{\prime} \text {. } \\
\text { L.P.F.A } \\
\text { Pires, B,L }\end{array}$ & 4 \\
\hline E2/ 2007 & $\begin{array}{l}\text { Compreendendo a } \\
\text { violência doméstica } \\
\text { a partir da } \\
\text { categorias de } \\
\text { gênero e geração. } \\
\text { Artigo de revisão }\end{array}$ & $\begin{array}{l}\text { Acta } \\
\text { Enferm }\end{array}$ & $\begin{array}{l}\text { Gomes, P.N } \\
\text { Diniz, F. M.N }\end{array}$ & 5 \\
\hline E3/ 2008 & $\begin{array}{l}\text { Violência de gênero } \\
\text { contra } \\
\text { trabalhadoras de } \\
\text { enfermagem em }\end{array}$ & $\begin{array}{l}\text { Rev. } \\
\text { Pública }\end{array}$ & $\begin{array}{l}\text { Oliveira, R. A } \\
\text { Oliveira, } \\
\text { L.P.F.A }\end{array}$ & 4 \\
\hline
\end{tabular}


hospital geral de

São Paulo. Artigo

original. Estudo

transversal

$\begin{array}{llll}\text { E4/ } 2009 \text { A violência de Esc Anna Nery } & \text { Guedes, N.R } \\ \text { gênero e o processo Rev Enferm } & \text { Silva, C.M.T.A } \\ \text { saúde doença das } & & \\ \text { mulheres. Artigo } & \\ \text { Original. Estudo } & & \\ \text { qualitativo } & & \end{array}$

\section{Categoria II - Violência doméstica ou sexual}

Os estudos apontam que, o principal agressor da mulher está no seio de seu próprio lar, pode ser ele o pai, irmão, marido ou mesmo os filhos. É fato também que, por motivos culturais e econômicos a mulher durante anos sofreu violência e não a denunciou as autoridades, para que esse ato parasse ou que alguma alternativa criminal fosse tomada.

Monteiro e Souza (2007) estudaram o cotidiano das mulheres em busca de respostas para entender melhor a causa das agredidas recusarem denunciar seus agressores. Essa atitude coloca as mulheres em situação de reclusão em seus próprios lares, em total submissão à figura masculina e como tal, toda e qualquer atitude de defesa seja entendida como rebeldia e desacato a figura "maior", o homem. A violência contra a mulher é um problema mundial e é discutido um episódio de saúde pública. Esse tipo de problema acarreta às mulheres vítimas uma série de sintomas físicos e emocionais, tais como: ansiedade, medo, sentimento de inferioridade, insegurança, baixa autoestima e grande sofrimento psíquico, que requer tratamento diferenciado com analistas. $O$ estudo concluiu que compete ao Estado realizar ações que visem a prevenção da violência e em caso de ocorrência da mesma, não só a mulher deve ser atendida, também o agressor deve ser instruído através de grupos de auto ajuda, no sentido de melhorar o crescente quadro da violência (TONET, 2007; WILHELM, 2007).

Schariber (2007) se dedicaram a estudar um grupo de mulheres vítimas de violência doméstica na zona rural de Pernambuco e na cidade de São Paulo, tendo como principal objetivo verificar a prevalência da violência sexual ou física nos grupos pesquisados. Os estudos mostraram que os maiores agressores foram seus próprios parceiros íntimos. Ao final o estudo apontou que nos dois grupos pesquisados a violência psicológica foi a que mais ocorreu, seguida da física e por último a sexual. Afirmou-se, portanto, que a mulher ainda é o alvo principal da discriminação de gênero, mesmo depois de tantas conquistas conseguidas, os homens ainda não as vem como parceiras e sim como um objeto de sua total posse.

Nesse mesmo sentido, Oliveira (2008) buscaram atualizar os números em relação ao tipo de violência é mais cometida contra as mulheres. Os autores apresentaram um estudo de campo com informações coletadas em um hospital geral na cidade de São Paulo entre os anos de 2005 e 2006. Os resultados apontaram para ações de agressão psicológica, física ou sexual e o agressor prevalente foi o seu parceiro íntimo.

Guedes (2009) ao analisar o quadro da violência conjugal na cidade de João Pessoa-PB, concluiu que as mulheres agredidas constantemente passam por sérios problemas de saúde e que esse fato influencia diretamente na conduta das mesmas diante de seu cotidiano. Os resultados denunciam a necessidade de maior preparo das equipes de saúde ao assistir esse tipo 
de vítima. Voltando a

prevalência da violência quanto a seu tipo Moura (2009) em um estudo dirigido na cidade de Brasília-DF constataram que a modalidade de violência psicológica foi a maior causadora de problemas de ajuste psicossocial na mulher agredida, depois foi apontada a violência física e por último a sexual. Levar esse dado para junto ao tema violência quanto a seu tipo.

Na Tabela 3, têm-se os artigos relacionados à violência de gênero indicando a classificação das forças, sendo que $12,5 \%$ doa artigos obtiveram nível 5 .

Tabela 3. Artigos relacionados à violência doméstica ou sexual.

\begin{tabular}{|c|c|c|c|c|}
\hline Estudo/Ano & Título/ Tipo de estudo & Periódico & Autores & Evidência/Nível \\
\hline E1/ 2007 & $\begin{array}{l}\text { Vivência da violência conjugal: } \\
\text { Fatos do cotidiano. } \\
\text { Artigo original. Estudo } \\
\text { qualitativo }\end{array}$ & $\begin{array}{l}\text { Texto } \\
\text { Contexto } \\
\text { Enferm }\end{array}$ & $\begin{array}{l}\text { Monteiro, SFC } \\
\text { Souza, OEI }\end{array}$ & 4 \\
\hline E2/ 2007 & $\begin{array}{l}\text { Percepção da violência } \\
\text { doméstica na perspectiva de } \\
\text { mulheres vitimadas. Artigo } \\
\text { original. Estudo qualitativo }\end{array}$ & $\begin{array}{l}\text { Psicol. } \\
\text { Argum. }\end{array}$ & $\begin{array}{l}\text { Ax Wilhelm. F } \\
\text { Tonet. J }\end{array}$ & 4 \\
\hline E3/ 2007 & $\begin{array}{l}\text { Violência contra a mulher, } \\
\text { coesão familiar e drogas. } \\
\text { Artigo original. Estudo tipo caso } \\
\text { e controle }\end{array}$ & $\begin{array}{l}\text { Rev. Saúde } \\
\text { Pública }\end{array}$ & $\begin{array}{l}\text { Rabello, M.P } \\
\text { Júnior, C.F.A }\end{array}$ & 4 \\
\hline E4/ 2007 & $\begin{array}{l}\text { Prevalência da violência contra } \\
\text { a mulher por parceiro íntimo } \\
\text { em regiões do Brasil. Artigo } \\
\text { original. Estudo transversal }\end{array}$ & $\begin{array}{l}\text { Rev. Saúde } \\
\text { Pública }\end{array}$ & $\begin{array}{l}\text { Scheraiber, B.L } \\
\text { Oliveira, } \\
\text { d'.L.P.F.A, et. al. }\end{array}$ & 4 \\
\hline E5/ 2008 & $\begin{array}{l}\text { O perfil de mulheres vitimizadas } \\
\text { e seus agressores. Artigo de } \\
\text { revisão. Estudo retrospectivo } \\
\text { documental }\end{array}$ & $\begin{array}{l}\text { Rev. Enferm. } \\
\text { UERJ }\end{array}$ & $\begin{array}{l}\text { Leôncio, L.K } \\
\text { Baldo, P.P, et. } \\
\text { al. }\end{array}$ & 5 \\
\hline E6/ 2009 & $\begin{array}{l}\text { Violências contra a mulheres } \\
\text { por parceiros íntimos em área } \\
\text { economicamente vulnerável, } \\
\text { Brasil, DF. Artigo original. } \\
\text { Estudo transversal }\end{array}$ & $\begin{array}{l}\text { Rev. Saúde } \\
\text { Pública }\end{array}$ & $\begin{array}{l}\text { Moura, A.B.L } \\
\text { Gandolfi, L, et. } \\
\text { AL. }\end{array}$ & 4 \\
\hline E7/ 2010 & $\begin{array}{l}\text { Violência entre parceiros } \\
\text { íntimos e consumo de álcool. } \\
\text { Artigo original. } \\
\text { transversal }\end{array}$ & $\begin{array}{l}\text { Rev. Saúde } \\
\text { Pública }\end{array}$ & $\begin{array}{l}\text { Zaleski, M. } \\
\text { Pinsky, I., et. al. }\end{array}$ & 4 \\
\hline E8/ 2011 & $\begin{array}{l}\text { Fatores associados à violência } \\
\text { física por parceiro íntimo em } \\
\text { usuárias de serviços de saúde. } \\
\text { Artigo original. Estudo } \\
\text { transversal }\end{array}$ & $\begin{array}{l}\text { Rev. Saúde } \\
\text { Pública }\end{array}$ & $\begin{array}{l}\text { Vieira, M.E } \\
\text { Perdona, C. S G } \\
\text { Santos, A.M }\end{array}$ & 4 \\
\hline
\end{tabular}




\section{RESULTADOS E DISCUSSÃO}

Com vistas ao objetivo do estudo de analisar a violência doméstica e sexual sofrida pela mulher brasileira no período de 2007 a 2011, consideramos que a violência contra a mulher ainda se encontra oculta nos lares brasileiros, embora na maioria das vezes não seja denunciada por medo dos agressores e por vergonha de exposição. Os dados da pesquisa revelam ainda que as consequências extrapolam os danos físicos como depressão e insônia e causam também lesões psicológicas. A violência contra a mulher já é considerada como um grande problema de saúde pública, portanto, necessita de maior atenção por parte das políticas públicas, assim como, da competência dos profissionais de saúde para a identificação dos casos, a fim de intervir e prevenir maiores danos às vítimas. Desse modo, a violência contra a mulher não se constrói apenas por relações de desigualdade e sentimento de superioridade por parte dos agressores, mas também, resulta de fatores externos como ingestão de bebidas alcoólicas, desemprego, e abuso de poder. Devido ao alto índice/incidência de violência contra a mulher foi criada a Lei 11.340 (Brasil) que cria mecanismos para coibir a violência doméstica e familiar contra a mulher e, estabelece ainda medidas de assistência e proteção às mulheres em situação de violência. Vale ressaltar que praticamente desde 2011, até os tempos atuais do ano de 2014, não tiveram ações públicas que mudassem o cenário da violência contra a mulher, ou seja, apresentadas nesta pesquisa. Nesse contexto, a realidade conduz acreditar que a nova legislação oferece o reconhecimento da violência contra as mulheres e identificará o problema social, e tecerá providências para o combate por meio de políticas públicas na intenção de colocar a mulher no centro do debate.

\section{REFERÊNCIAS}

BARRETO, A. C. (2009). Desenvolvimento Humano e Violência de Gênero: Uma Integração. Bioecológica. Psicologia: Reflexão e Crítica, 22 (1), 86-92.

BRASIL. Lei 11.340. (2006). Dispõe sobre a criação dos juizados de violência doméstica e familiar contra a mulher e dá outras providências. Diário Oficial da União, 8 (1:1).

COUTO, M. T.; SCHRAIBER, L. B.; D'OLIVEIRA, A. F. P. L.; KISS, L. B. (2006). Concepções de gênero entre homens e mulheres de baixa renda e escolaridade acerca da violência contra a mulher. Ciência Saúde Coletiva, 11 (suplemento), 1323-1332.

GOMES, N. P.; DINIZ, N. M. F.; ARAÚJO, A. J. S.; COELHO, T. M. F. (2007). Compreendendo a violência domestica a partir das categorias de gênero e geração. Acta Paulista de Enfermagem, 20 (4), 504-538.

GUEDES, R. N.; SILVA, A. T. M. C.; FONSECA, R. M. G. S. (2009). A violência de gênero e o processo saúde-doença das mulheres. Escola Anna Nery, 13 (3), 625-631.

LEÔNCIO, K.L.; BALDO, P. L.; JOÃO, V. M.; BIFFI, R. G.(2008). O perfil das mulheres vitimizadas e seus agressores. Revista de Enfermagem UERJ, 16 (3), 307-312.

MENDES, K. D. S.; SILVEIRA, R. C. C. P.; GALVÃO, C. M. (2008). Revisão integrativa: método de pesquisa para a incorporação de evidências na saúde e na enfermagem. Texto Contexto-Enfermagem, 17 (4), 758-764. 
MONTEIRO, C.F.S; SOUZA, I.E.O. (2007). Vivência da violência conjugal: Fatos do cotidiano. Texto Contexto em Enfermagem, 16 (1), 26-31.

MOURA, L. B. A.; GANDOLFI, L.; VASCONCELOS, A. M. N.; PRATESI, R. (2009). Violências contra mulheres por parceiro íntimo em área urbana economicamente vulnerável, Brasília, DF. Revista Saúde Pública, 43 (6), 944-953.

OLIVEIRA, A. R.; D'OLIVEIRA, A. F. P. L. (2008). Violência de gênero contra trabalhadoras de enfermagem em hospital geral de São Paulo (SP). Revista Saúde Pública, 42 (5), 868-876.

RABELLO, P. M.; CALDAS JÚNIOR, A. F. (2007). Violência contra a mulher, coesão familiar e drogas. Revista Saúde Pública, 41 (6), 970-978.

SAFFIOTI, H. I. B. (2001). Contribuições feministas para o estudo da violência de gênero. Cadernos Pagu, 16(1), 115-136.

SCHRAIBER, L. B.; D'OLIVEIRA, A. F. P. L.; FRANÇA-JUNIOR, I.; PORTELLA, A. P.; LUDERMIR, A. B.; VALENÇA, O.; COUTO, M. T. (2007). Prevalência da violência contra a mulher por parceiro íntimo em regiões do Brasil. Revista de Saúde Pública, 41 (5), 797-807.

VIEIRA, E. M.; PERDONA, G. S. C.; SANTOS, M. A. (2011). Fatores associados à violência física por parceiro íntimo em usuárias de serviços de saúde. Revista Saúde Pública, 45 (4), 730-737.

VILLELA, W. V.; LAGO, T. (2007). Conquistas e desafios no atendimento das mulheres que sofreram violência sexual. Caderno Saúde Pública, 23 (2), 471-475.

WILHELM, F.A.; TONET, J. (2007). Percepção sobre a violência doméstica na perspectiva de mulheres vitimadas. Psicologia Argumento, 25 (51), 401-412.

ZALESKI, M.; PINSKY, I.; LARANJEIRA, R.; RAMISETTY-MIKLER, S.; CAETANO, R. (2010). Violência entre parceiros íntimos e consumo de álcool. Revista Saúde Pública, 44 (1), 53-59. 